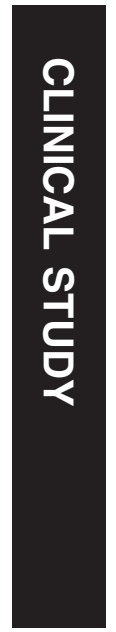

\title{
Survey of school children with visual impairment in Bradford
}

Abstract

This work was presented as a poster at the Institute of Health Research Conference 2000: Health of Children and Young People: Research Perspectives. University of Bradford 15th of September 2000.

Aims The aim of this survey was to determine the prevalence and aetiology of visual impairment in school children in Bradford.

Methods The case notes of school children with predominantly uncomplicated visual impairment were reviewed. Data including age, sex, race and information on visual diagnosis, heredity, degree of visual impairment and additional morbidity were collected.

Results Seventy-two children between the ages of 5 and 16 years were included in this survey. The male: female ratio was 2.1: 1 . Twenty-one children were Caucasian, 42 were of Pakistani and nine of other racial origin. The most common diagnoses were congenital nystagmus (19), ocular albinism (6), myopia (4), cataract (4) and microphthalmia (4). Twenty-five children had a genetically linked visual diagnosis and 31 had a family history of the same visual disorder.

Conclusions This survey showed similar causes of visual impairment as described in other studies on children with uncomplicated visual impairment and confirmed the previously described preponderance of boys. The proportion of Pakistani children in our study population was significantly higher than that in the general Bradford population, indicating a higher prevalence of visual impairment in this group. Children of Pakistani origin were significantly more likely to have genetically linked visual disease and a positive family history of the same visual disorder than children of Caucasian origin. This is probably due to
K Schwarz ${ }^{1,2}$, S Yeung ${ }^{1}$, N Symons ${ }^{1,3}$ and J Bradbury ${ }^{1,4}$ genetic factors and a higher proportion of consanguineous marriages in this population. Information about the prevalence and causes of visual impairment is important for adequate provision of special services and for developing preventive strategies. Eye (2002) 16, 530-534. doi:10.1038/ sj.eye. 6700059

Keywords: visual impairment; prevalence; aetiology

\section{Introduction}

Bradford has a multicultural childhood population with a substantial proportion of children from a non-Caucasian background. There are few data available showing what impact this has on the causes and prevalence of visual impairment in this population.

The aims of this survey were to review the available data and to investigate the causes and prevalence of visual impairment in schoolchildren attending Temple Bank School for the visually impaired or mainstream school in Bradford.

\section{Patients and methods}

The case notes of all children between the ages of 5 and 16 years resident in Bradford with visual impairment without any other major disabilities were reviewed. These children either attend Temple Bank School (the Bradford school for visually impaired children) or, if they attend mainstream school, are known to peripatetic staff in the 'visual community'. Children with multiple problems including visual impairment attending one of the other 11 Bradford special schools were not included. These children are not usually known to the Bradford visual impairment team and little information is available on the nature and severity of their visual impairment. 
This is mainly due to difficulties in assessing these usually severely disabled children.

We collected data available from the patients' case notes. These included demographic data, information on the visual diagnosis, the degree of visual impairment and on additional health problems.

The World Health Organisation (WHO) definitions ${ }^{1}$ were used to classify visual impairment and blindness.

\section{Results}

We identified 122 children between the ages of 5 and 16 years resident in Bradford with visual difficulties. Three sets of notes were missing. Of the 119 case notes reviewed, 44 children did not have visual impairment as defined by the $\mathrm{WHO}^{1}$ but had decreased vision. The vision of three children could not be formally assessed (two were uncooperative and one was too severely disabled). The case notes of the remaining 72 children were included in the analysis.

Forty-nine $(68 \%)$ of our patient group were boys and $23(32 \%)$ were girls giving a ratio of boys to girls of 2.1 to 1 . Twenty-one (29.2\%) patients were of Caucasian and $42(58.3 \%)$ were of Pakistani origin. The remaining nationalities were three Indian, one West Indian, one English/West Indian, one English/Pakistani and three unknown.

The mean age was 11 years at the time of the review. Thirty-three children were 5-10 years old and 39 children were 11-16 years old. Ten children were born prematurely. The mean birth weight for all children was $3 \mathrm{~kg}(1.06-4.95 \mathrm{~kg})$. Thirty-one (43\%) children had a family history of visual problems. In 25 $(34.7 \%)$ children a relative had the same visual disorder (16 siblings, four cousins, three parents, two grandparents) as the patient and 15 of these families were known to be consanguineous.

Sixty-nine children had a visual diagnosis; no diagnosis was available for three children. The diagnoses are detailed in Table 1.

The most common diagnosis in this patient group was congenital idiopathic nystagmus in 19 (27.5\%) patients. The clinical diagnosis was confirmed with an ERG in all patients. Eight out of the 19 (42\%) children with congenital idiopathic nystagmus had a family history for this disorder and 14 (74\%) of these children were boys. Twenty-three patients $(33 \%)$ in our group had nystagmus secondary to their underlying visual diagnosis. This was most commonly due to oculocutaneous albinism (six cases), high myopia (three) and optic nerve hypoplasia (three).

The second common diagnosis was ocular albinism accounting for six cases. There were four cases each of high myopia, cataract and microphthalmia. As a group
Table 1 Visual diagnoses in school children with visual impairment in Bradford

\begin{tabular}{|c|c|c|}
\hline & Diagnosis & Number \\
\hline \multirow[t]{2}{*}{ Cornea } & $\begin{array}{l}\text { Hereditary endothelial dystrophy of } \\
\text { the cornea }\end{array}$ & 2 \\
\hline & Sclerocornea & 1 \\
\hline \multirow[t]{4}{*}{ Uveal tract } & Rieger's syndrome & 1 \\
\hline & Bilateral aniridia & 1 \\
\hline & Oculocutaneous albinism & 6 \\
\hline & Coloboma & 1 \\
\hline \multirow[t]{2}{*}{ Lens } & Congenital cataract & 3 \\
\hline & Diabetic cataract & 1 \\
\hline \multirow[t]{12}{*}{ Retina } & Vitreoretinal type syndrome & 1 \\
\hline & Vitreoretinopathy_undefined & 1 \\
\hline & Retinal dystrophy & \\
\hline & Leber's amaurosis & 1 \\
\hline & Progressive cone dystrophy & 1 \\
\hline & Undefined & 1 \\
\hline & Macular dystrophy & \\
\hline & Stargardt's disease & 2 \\
\hline & Undefined & 1 \\
\hline & Toxoplasmosis retinitis & 2 \\
\hline & Retinopathy of prematurity & 2 \\
\hline & Retinoblastoma & 2 \\
\hline \multirow[t]{4}{*}{ Optic nerve } & Optic nerve hypoplasia & \\
\hline & Septal dysgenesis & 2 \\
\hline & Undefined & 1 \\
\hline & Optic nerve atrophy & 3 \\
\hline Visual pathways & Cortical visual impairment & 2 \\
\hline \multirow[t]{2}{*}{ Refractive errors } & High myopia & 4 \\
\hline & High hypermetropia & 1 \\
\hline \multirow[t]{4}{*}{ Other diagnoses } & Congenital idiopathic nystagmus & 19 \\
\hline & Microphthalmia & 4 \\
\hline & Congenital glaucoma & 2 \\
\hline & $\begin{array}{l}\text { Retinal artery/vein thrombosis } \\
\text { secondary to protein } C \text { deficiency }\end{array}$ & 1 \\
\hline
\end{tabular}

retinal problems were most common with 14 cases. Uveal tract problems accounted for nine cases and optic nerve abnormalities for six cases (see Table 1).

Forty-eight $(66.6 \%)$ children had additional visual diagnoses. Most of these were squints (29 patients) and nystagmus (23 patients), and these frequently occurred together. Thirty-three (45.8\%) children with visual problems had developmental delay or learning difficulties as recorded in their case notes. We were unable to determine the degree of disability from the case notes.

Nine $(12.5 \%)$ children had visual impairment as a result of an underlying condition. These included two children with cerebral palsy associated with optic atrophy and cortical visual impairment, two children with septooptic dysplasia with optic nerve hypoplasia and one child each with diabetes mellitus and Pierre Robin syndrome (myopia), protein C deficiency (retinal artery/vein thrombosis), Fraser syndrome (cryptophthalmos), diabetes mellitus (cataract) and 
autoimmune thrombocytopenic purpura (intracranial bleed causing corticovisual impairment).

Three children with congenital idiopathic nystagmus had additional diagnoses. One child had mild cerebral atrophy, one child had cleft lip and palate and coloboma and one child had midline facial cleft syndrome raising the possibility of secondary rather than idiopathic congenital nystagmus.

Eighteen children had other diagnoses not related to their visual problems. These were epilepsy (three), failure to thrive (three), mild hearing loss (one), cerebral palsy (two), ASD (one), ichthyosis (one), neurofibromatosis (one), fetal alcohol S (one), situs inversus (one), autism (one), lymphoma (one), androgen insensitivity $S$ (one) and hypotonia (one). Although some of these diagnoses can cause visual problems they were not thought to be responsible for the visual problems in the above cases.

Overall, $44(61 \%)$ of children had other medical problems and/or developmental problems in addition to their visual impairment.

\section{Discussion}

This survey was performed to determine the prevalence and causes of visual impairment in children with predominantly visual problems in Bradford. Visual impairment or blindness was the main health problem of all children included in this survey. Most children were able to attend mainstream school, while $26(36.1 \%)$ attended our local school for the blind. Many of these children would have been classified in other surveys as having uncomplicated visual impairment although $61 \%$ of our patients had additional health and/or developmental problems and patient selection was not based on this criterion.

According to the last available Office of Population Censuses and Surveys data ${ }^{2}$ in 1991, 78540 children between the ages of 5 and 16 were living in Bradford. The prevalence of visual impairment is therefore 72 in 78540 or 0.92 in 1000 school-aged children in Bradford. It is very likely that we have underestimated the prevalence of children with visual impairment in Bradford, as we did not include any children with multiple pathology attending one of the other Bradford special schools. Prevalence rates quoted in the literature vary greatly depending on the country in which the study was conducted, the patient group examined and on the level of ascertainment of cases. A recent study performed in Liverpool ${ }^{3}$ including all children with visual impairment showed a prevalence of visual impairment in children between 0 and 16 years of 1.81 per thousand. This number is much higher than our prevalence rate but this study included all children with multiple problems and pre-school children. Thirty-two per cent of the Liverpool cases had cortical visual impairment, which is usually associated with other neurological abnormalities. ${ }^{4}$

The prevalence of blindness in our study was 13 in 78540 or 0.16 in 1000 and, again, was thought to be an underestimate due to the exclusion of children with multiple problems. An English study ${ }^{5}$ in 1981 and an Irish study ${ }^{6}$ in 1991 including all known blind children both quoted a prevalence of 0.2 in 1000 but did not comment on coexisting pathology, although in the Irish study $27 \%$ of children were blind secondary to perinatal problems. This number is likely to have increased further as there has been a significant increase in patients with cortical visual impairment and retinopathy of prematurity during the 1990s. ${ }^{7}$ Again, many of these patients are likely to have multiple health problems secondary to prematurity.

Our study showed a large preponderance of boys with a male-female ratio of 2.1 to 1 . This has also been noted in previous studies. The Liverpool study ${ }^{3}$ and the Irish study ${ }^{6}$ showed a ratio of 1.2 to 1 while the ratios were between 1.37 and 2.0 to 1 in a recent survey of Nordic children. ${ }^{8}$ The male preponderance in visual impairment is usually ascribed to X-linked disorders and increased vulnerability of boys to pathological insult, in particular in the perinatal period..$^{3,8}$ Our study underreported cases with perinatal problems and in the five perinatal cases included, only two patients were boys. Congenital nystagmus and albinism can be X-linked disorders and in our study 14 out of 19 children with congenital nystagmus and five out of six children with albinism were boys.

Nevertheless, even after exclusion of these patients, the male-female ratio in our patient group was still 1.76 to 1. We are unable to explain the high number of boys in our study group and census data ${ }^{2}$ do not suggest a preponderance of boys in the school-age population in Bradford.

According to the last available census data, $70.8 \%$ of schoolchildren in Bradford are of English/European origin while $20.3 \%$ are of Pakistani heritage. ${ }^{2}$ In our study population only $29.2 \%$ of children were of Caucasian and $58.3 \%$ were of Pakistani origin. The proportion of Pakistani children in our population is significantly higher than in the general Bradford population indicating that the prevalence of visual impairment is higher in the Pakistani than in the Caucasian population. This is possibly due to the high rate of consanguineous marriages in the Pakistani population. Twenty-six of 42 (62\%) Pakistani children in this survey were known to have consanguineous parents. Two sets of parents were known to be unrelated and for the remaining 14 children no 
Table 2 Likelihood of visual diagnosis being genetically linked in our study population

\begin{tabular}{|c|c|c|c|c|}
\hline & Diagnosis & Number & $\begin{array}{c}\text { Family history of same } \\
\text { visual disorder }\end{array}$ & Race \\
\hline $\begin{array}{l}\text { Very likely genetically } \\
\text { determined }\end{array}$ & $\begin{array}{l}\text { Hereditary endothelial dystrophy of the cornea } \\
\text { Rieger's syndrome } \\
\text { Bilateral aniridia } \\
\text { Oculocutaneous albinism } \\
\text { Congenital cataract } \\
\text { Vitreoretinal type syndrome } \\
\text { Leber's anaurosis } \\
\text { Retinal dystrophy } \\
\text { Stargardt's disease } \\
\text { Congenital idiopathic nystagmus } \\
\text { Microphthalmia-Fraser syndrome }\end{array}$ & $\begin{array}{l}2 \\
1 \\
1 \\
6 \\
1 \\
1 \\
1 \\
1 \\
2 \\
8 \\
1\end{array}$ & $\begin{array}{l}\text { Yes } \\
\text { Yes } \\
\text { Yes } \\
4 \text { yes } 2 \text { no } \\
\text { Yes } \\
\text { Yes } \\
\text { Yes } \\
\text { Yes } \\
\text { Yes } \\
\text { Yes } \\
\text { Yes }\end{array}$ & $\begin{array}{l}\mathrm{pp}^{\mathrm{a}} \\
\mathrm{C}^{\mathrm{b}} \\
\mathrm{P} \\
\text { PPPPPP } \\
\mathrm{P} \\
\mathrm{P} \\
\mathrm{P} \\
\mathrm{P} \\
\mathrm{PP} \\
\text { PPPPPCCC } \\
\mathrm{P}\end{array}$ \\
\hline $\begin{array}{l}\text { Possibly genetically } \\
\text { linked }\end{array}$ & $\begin{array}{l}\text { Sclerocornea } \\
\text { Congenital coloboma } \\
\text { Congenital cataract } \\
\text { Vitreoretinopathy } \\
\text { Progressive cone dystrophy } \\
\text { Undefined macular dystrophy } \\
\text { Optic nerve hypoplasia/atrophy } \\
\text { Congenital idiopathic nystagmus } \\
\text { Microphthalmia } \\
\text { Congenital glaucoma } \\
\text { High myopia ?Sticklers }\end{array}$ & $\begin{array}{c}1 \\
1 \\
2 \\
1 \\
1 \\
1 \\
5 \\
11 \\
3 \\
2 \\
1\end{array}$ & $\begin{array}{l}\text { No } \\
\text { No } \\
\text { No } \\
\text { No } \\
\text { No } \\
\text { No } \\
\text { No } \\
\text { No } \\
\text { No } \\
\text { No } \\
\text { No }\end{array}$ & $\begin{array}{c}\mathrm{C} \\
\mathrm{C} \\
\mathrm{PP}^{\mathrm{c}} \\
? \\
\mathrm{P} \\
\mathrm{C} \\
\mathrm{CCCPP} \\
8 \mathrm{P} 3 \mathrm{C} \\
\mathrm{CO} \mathrm{P} \\
\mathrm{CP} \\
\mathrm{P}\end{array}$ \\
\hline $\begin{array}{l}\text { Not genetically } \\
\text { linked }\end{array}$ & $\begin{array}{l}\text { Diabetic cataract } \\
\text { Toxoplasmosis retinitis } \\
\text { Retinopathy of prematurity } \\
\text { Retinoblastoma } \\
\text { Cortical visual impairment } \\
\text { High myopia } \\
\text { High hypermetropia } \\
\text { Retinal artery/vein thrombosis } \\
\text { Optic nerve hypoplasia-intrauterine cause }\end{array}$ & $\begin{array}{l}1 \\
2 \\
2 \\
2 \\
2 \\
3 \\
1 \\
1 \\
1\end{array}$ & $\begin{array}{l}\text { No } \\
\text { No } \\
\text { No } \\
\text { No } \\
\text { No } \\
\text { No } \\
\text { No } \\
\text { No } \\
\text { No }\end{array}$ & $\begin{array}{l}\mathrm{P} \\
\mathrm{PO} \\
\mathrm{OC} \\
\mathrm{CP} \\
\mathrm{OC} \\
\mathrm{CPP} \\
\mathrm{O} \\
\mathrm{P} \\
\mathrm{P}\end{array}$ \\
\hline
\end{tabular}

${ }^{\text {ap }}$, Pakistani origin.

${ }^{\mathrm{b}} \mathrm{C}$, Caucasian origin.

??, racial origin unknown.

${ }^{\mathrm{d}} \mathrm{O}$, other racial origin.

information was available on consanguinity. None of the Caucasian children in the survey were known to have consanguineous parents. Fifty-five per cent of Pakistani children had a positive family history for the same visual disorder they were affected with, while this was the case in only $29 \%$ of English children, suggesting a stronger genetic link in this population.

The causes of visual impairment vary greatly depending on the chosen study group. It is well recognised that in countries with good health services genetic factors are the prevailing cause of childhood blindness, ${ }^{5}$ while in less developed countries acquired diseases like acquired cataract are most common. ${ }^{8}$ In our study it was thought to be very likely in 25 (36\%) children that they had genetically determined disease (see Table 2), 21 (84\%) of these children were of Pakistani origin. Thirty-one $(44 \%)$ children in the study group had a family history of the same visual problem suggesting a strong genetic component in this population. These figures compare well with the results of the Edinburgh study, ${ }^{9}$ which examined blind children in a School for the Blind, sampling from a similar study population as in our study. In this study $36 \%$ of cases had very probably hereditary disease and a further $17 \%$ possibly had hereditary disease but no comment on ethnic grouping was made in this study. The Liverpool ${ }^{3}$ study also quotes a similar figure of at least $56 \%$ of patients with uncomplicated visual impairment being likely to have genetically determined disease.

Another study conducted in the West Bank and Gaza Strip ${ }^{10}$ also confirmed the high incidence of hereditary visual disease in a population with a high proportion of consanguineous marriages. In this study $62 \%$ of children with severe visual impairment or blindness were the product of a consanguineous marriage, $57 \%$ had a positive family history for the same visual disorder and in $54.9 \%$ of patients visual 
impairment or blindness was thought to be due to hereditary factors. Interestingly, the incidence of acquired visual disease was only $8.1 \%$ in this very poor population, suggesting that consanguinity was a more influential cause of visual problems than economic factors. The most common diagnosis in our study was congenital nystagmus with 19 (26.4\%) cases. The next common diagnoses were albinism (six) and high myopia (four). There were also eight children with hereditary retinopathy. These results are similar to the results of the Liverpool study where the four most common diagnoses in a slightly different patient group of children with uncomplicated visual impairment were albinism, hereditary retinopathy, congenital idiopathic nystagmus and refractive errors.

Congenital idiopathic nystagmus, which was the most common diagnosis in our patient group, is thought to have a prevalence of up to 1 in 1000 in the general population with a variable degree of severity. ${ }^{11}$ It is therefore a common cause of visual impairment but does not generally cause blindness. This explains why it is a common diagnosis in studies on children with visual impairment like our study but not in studies on childhood blindness like the Irish national survey. ${ }^{6}$

The main difficulty we had with this survey was to obtain information on all children with visual impairment in Bradford. We could not include children with visual impairment attending any of the other Bradford special schools, as there was no system in place that identifies all these children. Difficulties with case ascertainment have also been noted in other studies, 3,6 and it is thought that the incidence of visual impairment has generally been underestimated in the past. ${ }^{3}$ Social security registration data in this country are unreliable as registration is not compulsory and cases are underreported. In our study only $50 \%$ of children with visual impairment were known to be registered. In many Nordic countries registration is compulsory resulting in a better case ascertainment and more information available. ${ }^{9}$

Overall, we do think that this survey has produced useful data. Although it has underestimated the overall prevalence of visual impairment in schoolchildren in Bradford, it has given us a better understanding of the visual and associated problems of children with visual impairment in Bradford. It has confirmed findings of similar surveys regarding the prevailing diagnoses and the preponderance of boys in children with visual impairment. We have also demonstrated a higher prevalence of visual morbidity in Pakistani compared to English children, which is most likely related to inherited factors. For children with multiple disabilities, including visual impairment, better assessment tools and registration systems need to be developed to help to provide adequate services for these children and to help their families. As found in this survey, $61 \%$ of children had other health problems in addition to their visual impairment, which causes an added burden for their carers. A national study on severe visual impairment and blindness in children has recently been conducted by the British Paediatric Surveillance Unit, ${ }^{12}$ which will hopefully address some of these issues.

\section{References}

1 WHO. Guidelines for Programmes for the Prevention of Blindness. WHO: Geneva, 1979.

2 Office of Population Census and Surveys. 1991 census, County report, West Yorkshire Part I. London HMSO.

3 Rogers M. Vision impairment in Liverpool: prevalence and morbidity. Arch Dis Child 1996; 74: 299-303.

4 Huo R, Burden S, Hoyt C et al. Chronic cortical visual impairment in children: aetiology, prognosis, and associated neurological deficits. $\mathrm{Br} J$ Ophthalmol 1999; 83: 670-675.

5 Foster A, Gilbert C. Epidemiology of childhood blindness. Eye 1992; 6: 173-176.

6 Goggin M, O'Keefe M. Childhood blindness in the Republic of Ireland: a national survey. Br J Ophthalmol 1991; 75: 425-429.

7 Steinkuller PG, Du L, Gilbert C et al. Childhood blindness. J Aapos 1999; 3: 26-32.

8 Rüse R, Flage T, Hansen E et al. Visual impairment in Nordic children: sex distribution. Acta Ophthalmol 1992; 70: 605-609.

9 Phillips C, Levy A, Newton $\mathrm{M}$ et al. Blindness in schoolchildren: importance of heredity, congenital cataract, and prematurity. Br J Ophthalmol 1987; 71: 578584 .

10 Elder MJ, De Cock R. Childhood blindness in the West Bank and Gaza Strip: prevalence, aetiology and hereditary factors. Eye 1993; 7: 580-583.

11 Forssman B, Ringner B. Prevalence and inheritance of congenital nystagmus in a Swedish population. Ann Hum Genet 1971; 35: 139-147.

12 Royal College of Paediatrics and Child Health. British Paediatric Surveillance Unit. Annual Report 1999/2000, p 34. 